\title{
PESQUISA EM LITERATURA E INTERDISCIPLINARIDADE: UM RELATO DE EXPERIÊNCIA NA FORMAÇÃO DOCENTE EAD
}

\author{
https://doi.org/10.29327/3860.11.19-9
}

\author{
Cristina Rothier Duarte ${ }^{1}$ \\ Girlene Marques Formiga ${ }^{2}$ \\ Márcia de Oliveira Alves ${ }^{3}$
}

\section{RESUMO}

A organização curricular do curso de Letras, modalidade a distância, do IFPB oferece os componentes Seminário Interdisciplinar I, II, III e IV, com o mister de que os docentes em formação inicial desenvolvam pesquisas que articulem as teorias trabalhadas na graduação com a vivência no ambiente escolar. Diante da importância que esses componentes apresentam para o desenvolvimento do pensamento crítico e da vocação investigativa que devem residir no professor, nesta pesquisa, dedicar-nos-emos a descrever, mediante um relato de experiência, como se desenvolvem notadamente os Seminários Interdisciplinares II e IV dedicados à área de Literatura. Como objetivos específicos, apresentaremos sua previsão no Projeto Pedagógico; indicaremos como esses componentes curriculares são apresentados para os graduandos; e refletiremos sobre sua contribuição para a formação do cursista da modalidade EaD. A metodologia empregada será descritiva-interpretativa de cunho qualitativo, em que, a partir do estudo do Projeto Pedagógico e da apresentação da disciplina no ambiente virtual de aprendizagem - Plataforma Moodle - apresentaremos o funcionamento do componente Seminário Interdisciplinar II e IV, bem como utilizaremos a descrição contextual e estrutural para o relato de experiência. Como resultado, é possível observar que, por meio dos Seminários Interdisciplinares, os graduandos são introduzidos no campo da pesquisa científica, uma vez que recebem, durante as orientações que precedem o produto final do componente - os resultados da investigação - instruções tanto no tocante aos aspectos conteudistas, quanto formais da pesquisa, bem como, após a pesquisa concluída, devem proceder com a apresentação em modalidade similar às comunicações orais tão frequentes em eventos acadêmicos.

Palavras-chave: Relato de experiência; Seminário Interdisciplinar; Literatura; EAD; IFPB.

\footnotetext{
${ }^{1}$ Especialista em Ciências da Linguagem com Ênfase no Ensino da Língua Portuguesa - UFPB, Bacharel em Direito UFMT, graduanda em Letras - língua portuguesa - IFPB, mestranda em Letras - PPGLE UFPB

2 Doutorado em Letras pela Universidade Federal da Paraíba, Brasil(2009) Classe D - Padrão/nível 404 do Instituto Federal de Educação, Ciência e Tecnologia da Paraíba, Brasil

3 Doutoranda em Humanidades e Artes, graduação em Ciência da Computação pela Universidade de Marília (1992), especialista em Planejamento Educacional e em Educação a distância, professora do CEFET MT desde 1994, redistribuída para o IFPB em 2008.
} 


\begin{abstract}
The curricular organization of the distance learning course of the IFPB offers the components Interdisciplinary Seminar I, II, III and IV, with the aim that the teachers in initial formation develop research that articulate the theories worked in the graduation with the experience in the school environment. In view of the importance of these components for the development of critical thinking and the research vocation that should reside in the teacher, in this research, we will describe, through an experience report, how the Interdisciplinary Seminars II and IV dedicated to the Literature. As specific objectives, we will present its prediction in the Pedagogical Project; we will indicate how these curricular components are presented to undergraduates; and we will reflect on his contribution to the training of ODL trainee. The methodology used will be descriptive-interpretative qualitative, in which, from the study of the Pedagogical Project and the presentation of the discipline in the virtual learning environment Moodle Platform - we will present the operation of the Interdisciplinary Seminar II and IV component, as well as using the contextual and structural description for the experience report. As a result, it is possible to observe that, through Interdisciplinary Seminars, undergraduates are introduced into the field of scientific research, since they receive, during the guidelines that precede the final product of the component - the results of the investigation - instructions both regarding aspects of the research, as well as, after the research completed, should proceed with the presentation in a similar way to the oral communications so frequent in academic events.
\end{abstract}

Keywords: Experience report; Interdisciplinary Seminar; Literature; ODL; IFPB.

\title{
INTRODUÇÃO
}

A formação docente em Letras tem sido um constante mote para discussões acadêmicas e pesquisas científicas, devido, em grande parte, ao controverso lugar da Literatura na escola e a, consequente, crise da leitura. De acordo com Santos e Winkeler (2012), desde o final da década de 1970, vem se debatendo acerca do tema, sobretudo, no que diz respeito à sua vinculação com a formação docente, já que, conforme os autores, "[a] a crise da leitura instaurada no processo de formação de professores traz à luz a problemática de uma formação leitora deficiente dos futuros professores” (2012, p. 2).

Nesse contexto, o Projeto Pedagógico de Licenciatura em Letras, habilitação em 
Língua Portuguesa, modalidade EaD, do IFPB, apresenta uma organização curricular em que, entre os seis eixos que abrangem conjuntos de componentes curriculares, está o eixo articulador disciplinaridade e interdisciplinaridade:

O eixo articulador entre disciplinaridade e interdisciplinaridade é formado por um núcleo de problemas ou temas geradores que exigirá dos alunos a integração e aplicação dos conteúdos teóricos abordados nos diferentes eixos de estudo. Para tanto, o Curso está estruturado de forma que sejam realizados alguns seminários interdisciplinares no final de semestres, os quais devem abordar questões envolvendo a experiência profissional dos alunos ou problemas identificados na prática escolar [...] (IFPB, 2012, p. 41).

De acordo com o Projeto Pedagógico, a organização curricular do curso busca suprir lacunas que advêm de uma formação desarticulada, ou seja, de uma formação que não intercambia conhecimentos teóricos e práticos, porque baseada em um “enciclopedismo estéril e inútil” (IFPB, 2012, p. 32).

Nessa conjuntura, a fim de se desenvolver no docente em formação inicial competências condizentes ao estabelecimento de relações entre as diversas teorias estudadas nos componentes curriculares do curso, durante a graduação, bem como entre essas teorias e o exercício da docência, o Projeto Pedagógico prevê, no grupo de componentes que compõem a formação pedagógica requisitada pelas Diretrizes Curriculares Nacionais (Resolução n. 18, de 13 de março de 2002), as disciplinas Seminário Interdisciplinar I, II, III e IV. Esses Seminários apresentam correlação com as duas grandes áreas de Letras, Linguística e Literatura, além de contemplar o eixo referente à formação didático-pedagógica, sendo o I e o III destinados a pesquisas na área de Língua e Linguística; e o II e IV, a pesquisas na área de Literatura. Note-se, contudo, que, neste relato de experiência, trataremos apenas dos Seminários Interdisciplinares II e IV, por se referirem à área objeto de estudo das autoras.

Voltando-nos ao que estabelece o Projeto Pedagógico do Curso, na seção "ementário e bibliografia", a disciplina Seminário Interdisciplinar II, ofertada no $3^{\circ}$ período do curso com uma carga horária de 15 horas, equivalendo a 1 crédito, sem exigência de pré-requisitos, poderá abranger tanto os conteúdos ministrados nos componentes do semestre em curso quanto dos anteriores.

No plano de ensino constante do Ambiente Virtual de Aprendizagem estão inclusas as disciplinas: Introdução aos Estudos Literários, Teoria Literária I, Literatura 
Brasileira I, Literatura e Ensino e Literatura Portuguesa I. Tendo em vista que o Seminário Interdisciplinar é um componente sistematizado em torno de diferentes âmbitos de conhecimento profissional, há flexibilidade de elaboração da ementa.

Desse modo, as ações se realizam processualmente no decorrer do semestre, considerando os conhecimentos construídos e socializados pelos estudantes, definidos pelos aportes teóricos e discussões nos componentes curriculares da área em foco, notadamente no que se refere aos temas de orientações ligados à Literatura e à formação didático-pedagógica.

No que diz respeito ao Seminário interdisciplinar IV, referente ao $5^{\circ}$ período do curso, os conteúdos, especificamente, voltar-se-ão para a área de Literatura, concentrando-se nos conteúdos atinentes aos componentes curriculares cursados nos períodos $1^{\circ}, 2^{\circ}, 3^{\circ}, 4^{\circ}$ e $5^{\circ}$ - Introdução aos Estudos Literários; Literatura e Ensino; Teoria Literária I e II; Literatura Brasileira I, II e III; Literatura Portuguesa I e II; Metodologia do Ensino de Literatura. A carga horária também é de 15 horas/aula, equivalendo a 1 crédito, e não há pré-requisitos.

Importante notar a relevância da presença de componentes como estes na organização curricular de uma Licenciatura, bem como a sua consideração como objeto de estudo. Os Seminários Interdisciplinares, em conjunto com outros componentes pedagógicos como Metodologia do Ensino de Língua Portuguesa, Metodologia do Ensino de Literatura e Estágio Supervisionado Obrigatório, apresentam-se como experiências acadêmicas que relacionam teoria e prática com intuito de apresentar ao docente em formação uma gradativa inserção no ambiente escolar, além de, especialmente no caso dos Seminários, introduzi-los no campo da pesquisa científica e conduzi-los no caminho "de superação da visão fragmentada nos processos de produção e socialização do conhecimento" (THIESEN, 2014, p. 545).

No que diz respeito ao estudo interdisciplinar de Literatura, Martins entende que

[1] eitura, literatura e teoria literária deveriam estar estreitamente relacionadas no meio escolar, devido a vários motivos, dentre os quais citamos: a própria natureza interdisciplinar do ato de ler que envolve contribuições de diversas áreas. No caso da leitura literária, o ato de ler é influenciado por estratégias cognitivas, lingüísticas (sic), metalingüísticas (sic), conhecimento do policódigo literário, noção de gênero literário, estilo de época no qual o texto está inserido, enfim, um conjunto de noções determinantes na interação do leitor com o texto; [...] (2005, p. 514). 
Com efeito, o professor muitas vezes somente poderá compreender essa interdisciplinaridade se vivenciada durante a sua formação. Sendo assim, como o intuito de promover essa experiência, os Seminários Interdisciplinares de Literatura oportunizam aos graduandos de Letras do IFPB a experiência de, ainda na formação inicial, realização de um estudo de natureza científica que promove o conhecimento articulado da Literatura e, por via de consequência, uma formação crítica e contextualizada para a realidade que lhes espera no ambiente escolar.

Essa prática pedagógica vivenciada no curso representa uma concepção freireana (FREIRE, 2013) que defende a pesquisa como princípio articulador da produção do conhecimento, haja vista a sua valorização ao processo de ensino e aprendizagem. Ideia semelhante é apresentada por Pedro Demo (2004), quando defende a pesquisa como princípio educativo e científico. Segundo o autor, como todo processo formativo, a pesquisa,

[...] baseia-se na habilidade de dentro para fora do aluno, cuja iniciativa é constitutiva do processo, permanecendo o professor como orientador e avaliador; aprende-se que conhecer é basicamente questionar, não afirmar, constatar, verificar; aprende-se a ler autor para se tornar autor; aprende-se a argumentar, deixando de lado o argumento de autoridade e construindo a autoridade do argumento; aprende-se a convencer sem vencer (DEMO, 2004, p.18).

Percebe-se, posto isso, a relevância do presente estudo, que se dá também em razão da contribuição que poderá oferecer para a comunidade científica, notadamente, a pertencente às áreas que se dedicam ao estudo de metodologias empregadas na modalidade de educação a distância.

\section{METODOLOGIA}

O curso de Licenciatura em Letras com habilitação em Língua Portuguesa, modalidade a distância, foi criado em 2012, “contemplando os objetivos e finalidades das políticas públicas educacionais vigentes, como o Plano Nacional de Educação, o Plano Nacional de Formação de Professores e as políticas de ensino do IFPB" (FORMIGA; DUARTE, no prelo 2017).

Desde a sua primeira turma, cuja oferta de vagas se deu no ano de surgimento do 
curso, os alunos devem, a partir do $2^{\circ}$ período, cumprir os créditos relativos aos componentes Seminário Interdisciplinar I, II, III e IV, que, conforme já apresentado, visam ao intercâmbio entre conhecimentos teóricos e práticos próprios da vida docente de forma interdisciplinar.

Como em todo curso da modalidade EaD, esses componentes são apresentados no ambiente virtual de aprendizagem que, no caso do IFPB, é a plataforma Moodle, e são ministrados pelo professor formador e pelo tutor. No entanto, em se tratamento da natureza de pesquisa acadêmica dos Seminários Interdisciplinares, esses componentes apresentam uma peculiaridade: a presença do professor orientador.

Cabem aos professores formadores e tutores, o ministério e o acompanhamento da disciplina, que se dá pela disponibilização de conteúdos pertinentes ao tratamento científico por meio da interdisciplinaridade; a abertura de fóruns de atividades que precedem a elaboração do trabalho final dos alunos e fórum de dúvidas; a apresentação dos temas e seus respectivos professores orientadores; bem como o estabelecimento das normas que regerão o Seminário, mediante a cessão de modelo de plano de trabalho (para o Seminário II), de trabalho final gênero artigo científico (Seminário IV), de slides utilizados na apresentação oral; estabelecimento de prazos e demais orientações pertinentes ao gênero seminário.

O professor orientador será responsável pela indicação dos rumos que seus orientandos deverão tomar durante a pesquisa, como sugestão do corpus e da base teórica para realização do estudo (indicação e ou disponibilização de obras especializadas e de textos científicos); verificação dos procedimentos e métodos empregados. Seu papel, pois, deverá ser o de oferecer uma orientação adequada para a realização de um trabalho de qualidade, tendo em vista que uns dos objetivos da disciplina é submeter o produto final da pesquisa para a publicação em algum periódico ou revista especializada.

Outra especificidade do componente Seminário Interdisciplinar é oportunidade do contato presencial e do exercício da oralização em sala, procedimentos mais raros em cursos de EaD. Desse modo, no dia da apresentação dos trabalhos, os alunos devem se dirigir ao polo do seu curso, quando, então, dar-se-á o momento em que compartilharão o conhecimento adquirido a partir da investigação realizada durante o período letivo e serão avaliados de acordo com os critérios avaliativos apresentados previamente no 
Ambiente Virtual de Aprendizagem (2017), os quais passamos a elencar:

1. O seminário interdisciplinar equivale à avaliação presencial de todos os componentes curriculares envolvidos, cuja nota é 100 pontos. A nota dada refere-se à soma da análise da produção acadêmica escrita (40 pontos) e da Apresentação oral (60 pontos).

2. A produção acadêmica (Plano de trabalho ou Artigo Científico) será avaliada pelo professor orientador, que atribuirá uma nota ao grupo, na Sala de Seminário, denominada Espaço para Avaliações dos Seminários. O professor orientador, para efeitos de avaliação, observará a organização sequencial, a argumentação, a profundidade do tema, a correção gramatical e a correlação do conteúdo.

3. A Apresentação oral será avaliada por uma banca, composta por professores dos componentes curriculares envolvidos na proposta interdisciplinar, presentes no Polo, que atribuirão nota individual aos membros do grupo, na Sala de Seminário (Espaço para Avaliações dos Seminários - Apresentação Oral do Seminário). Para essa avaliação serão considerados os seguintes itens: organização da apresentação, clareza nas informações, correção linguística e domínio de conteúdo ${ }^{4}$.

Para fins didáticos, os procedimentos metodológicos dos Seminários, são distribuídos em três momentos: fase inicial da pesquisa, fase de orientação e fase de apresentação de resultados da pesquisa.

Durante a fase inicial do Seminário, o professor formador apresenta o calendário, o conteúdo sobre interdisciplinaridade e os fóruns de discussão. Concluída essa fase, o professor, então, disponibiliza um fórum com os temas apresentados pelos professores orientadores da área de Literatura, estabelecendo prazo para que cada grupo de alunos escolha o tema que irá trabalhar. À medida que os grupos se formam, e os temas são escolhidos, estes não podem ser selecionados por outro grupo do mesmo polo.

A partir daí, iniciam-se as orientações e as pesquisas. Para tanto, um novo fórum é

\footnotetext{
${ }^{4}$ Cada professor estabelecerá os critérios relativos ao domínio de conteúdo do trabalho orientado.
} 
criado, o fórum de orientação, que se destina às discussões de cada um dos grupos e seus respectivos orientadores acerca de tudo que se relacione à realização da pesquisa do tema selecionado.

Realizada a fase de investigação, estando com o plano de trabalho (Seminário II) ou o artigo científico (Seminário IV) pronto, resta aos alunos a apresentação de seus resultados. Dessa forma, nos dias e polos estabelecidos para apresentação, os grupos devem se fazer presentes.

A apresentação dos quatro Seminários Interdisciplinares consiste na exposição oral da pesquisa para uma plateia de alunos do curso de Letras e dois professores avaliadores. Ao comunicar o seu trabalho os alunos, como o apoio de slides, deverão fazê-lo em 15 minutos, com mais 5 minutos de tolerância, devendo abordar: uma apresentação prévia do tema tratado; o objetivo geral e os específicos; a metodologia; o aporte teórico empregado na pesquisa; a aplicação dessa teoria ao corpus (estudo de caso, proposta pedagógica, análise de obra etc.); os resultados; e, por fim, a bibliografia utilizada na pesquisa.

Apresentado o trabalho, os professores avaliadores poderão fazer sugestões, pedir esclarecimentos entre outras intervenções. À apresentação, conforme já elencado, é atribuída uma nota de 0 (zero) a 60 (sessenta) pontos, que somados à nota da produção escrita, que poderá variar de 0 (zero) a 40 (quarenta), totalizará, no mínimo, 0 (zero) e, no máximo, 100 (cem) pontos.

Como dito, no caso do Seminário IV, a produção escrita será do gênero artigo científico, de maneira que deverá obedecer às normas da ABNT em seus diversos aspectos, sobretudo, no que diz à referência e à citação, a fim de conferir o devido respeito aos direitos autorais, um dos aspectos levados em consideração para o fim de atribuição de nota. Uma vez apresentado e ajustado, caso necessite, os alunos poderão submeter o trabalho a uma revista ou a um periódico científico, ou ainda apresentá-lo em algum evento acadêmico da área.

\section{ANÁLISE E DISCUSSÃO}

A interdisciplinaridade converge em práticas metodológicas que abordam o objeto de estudo como um todo, sem fragmentação do conhecimento, oportunizando aos 
alunos uma formação crítica, já que, diante da realidade permeada por sua complexidade, o estudo não poderia ser outro que não o complexo, ou seja, o interdisciplinar.

A disciplina Seminário Interdisciplinar é o momento em que os cursistas de Letras do IFPB aplicam a teoria à prática, ou seja, quando empregam aquilo que aprenderam no decorrer das disciplinas em um projeto de pesquisa que será desenvolvido no decorrer do período.

O Curso de Licenciatura em Letras com habilitação em Língua Portuguesa, na modalidade a distância, considera, em sua proposta pedagógica, a articulação entre os conhecimentos abordados pelos diversos componentes curriculares no decorrer do Curso. A organização de sua estrutura curricular - baseada na integração entre teoria e prática, capaz de garantir ao egresso condições de superar os desafios que se apresentem no exercício da profissão - abrange as dimensões de natureza acadêmica, profissional e de pesquisa.

Tal articulação está mais sistematizada por meio do componente curricular Seminário Interdisciplinar, ministrado entre os períodos $2^{\circ}$ e $5^{\circ}$, conforme consta da Matriz Curricular. Os componentes, estruturados sob a perspectiva de disciplinaridade, trandisciplinaridade e multidisciplinaridade, norteiam-se por meio de um núcleo de problemas ou temas geradores que exigirá dos estudantes a integração e a aplicação dos conteúdos teóricos abordados nos diferentes eixos de estudo.

A cada período, os Seminários estão formatados de modo a integrarem conhecimentos de Língua e formação didático-pedagógica e Literatura na formação do professor com atividades desenvolvidas em grupos sob a orientação de professores. Como delineado no decorrer deste artigo, o fruto desse trabalho resultará em apresentação oral nos encontros presenciais, que ocorrem semestralmente, envolvendo os componentes curriculares ministrados no semestre.

Além de esses componentes oportunizarem o conhecimento prático e interdisciplinar, preparando o cursista para a vida docente, os Seminários introduzem-no na experiência investigativa de cunho científico, procurando inserir a pesquisa como elemento constituinte da prática docente, fato que colabora para a formação permanente desse profissional, uma vez que propiciar a atitude reflexiva sobre o seu saber e sobre o seu fazer. Nesse sentido, estabelece a Resolução MEC/CNE/CP $n^{\circ} 2$, de $1^{\circ}$ de julho de 
2015, que define as Diretrizes Curriculares Nacionais para a formação inicial em nível superior e para a formação continuada:

\footnotetext{
$\S 5^{\circ}$ São princípios da Formação de Profissionais do Magistério da Educação Básica:

$[\ldots]$

V - a articulação entre a teoria e a prática no processo de formação docente, fundada no domínio dos conhecimentos científicos e didáticos, contemplando a indissociabilidade entre ensino, pesquisa e extensão; [...] (BRASIL, 2015, on line).
}

Como se vê a articulação entre teoria e prática associada à pesquisa constitui um dos princípios estabelecidos para a formação docente em nível superior. Nesse contexto, os componentes em comento permitem que o discente de Letras do IFPB vivencie essa experiência logo no início de sua vida acadêmica, oportunizando o despertar para pesquisa, o que, por sua vez, corrobora com o que Fontana defende: "a defesa da formação do professor reflexivo e pesquisador, em contraposição ao professor tecnicista, assume a perspectiva da qualificação da ação docente para atuação crítica e transformadora em contextos complexos da prática educativa" (FONTANA, 2007, p. $15)$.

E mais, outorgam ao discente o desenvolvimento da competência de comunicação oral. Ao participarem dos Seminários, quando da apresentação dos resultados de suas pesquisas, os alunos deverão expor oralmente todo o percurso de estudo até às conclusões obtidas de modo similar aos eventos promovidos no âmbito acadêmico.

Tal experiência, em suma, insere o graduando na prática investigativa, impulsionando, consequentemente, para um fazer docente analítico-reflexivo, de maneira que contribui para um exercício profissional mais consciente e, portanto, capaz de contribuir para a construção de uma sociedade melhor.

\section{CONCLUSÃO}

Nascida sob a égide de um curso em formação em seus procedimentos metodológicos na instituição, esta pesquisa registra um pouco das inquietações das pesquisadoras - docentes e estudante do curso de Letras do IFPB -, visando à reflexão 
acerca de algumas práticas pedagógicas adotadas em uma modalidade ainda nova capaz de conduzir nossos educandos a uma postura autônoma, crítica e emancipatória do conhecimento e seu uso nas situações reais.

Os procedimentos adotados nos Seminários Interdisciplinares visam à promoção da indissociabilidade entre o ensino e a pesquisa no Curso de Licenciatura em Letras, incorporando os princípios da interdisciplinaridade - a qual estabelece diálogo entre os saberes - e da contextualização, visando à (re)significância e funcionalidade dos conteúdos. No caso dos Seminários II e IV, a aplicação mais direta com a área da Literatura e da formação didático-pedagógica.

Assim, a experiência dos Seminários Interdisciplinares II e IV realiza a aplicação da interdisciplinaridade ao campo da Literatura em associação com componentes curriculares ministrados durante o semestre de oferta do Seminário, considerando ainda outros componentes da área vistos em períodos anteriores. Nessa perspectiva, busca desenvolver as habilidades necessárias nos futuros educadores ao confeccionar e aplicar instrumentos e estratégias didáticas necessários para dinamizar o ensino desses saberes, promovendo a interlocução, a reflexão metodológica e a prática entre campos disciplinares semelhantes e diferentes.

O Seminário Interdisciplinar IV encerra o enfoque da interdisciplinaridade como proposta de formação curricular apresentada ao nosso licenciando em Letras como componente curricular. Esse elo entre o entendimento das disciplinas nas suas mais variadas áreas, porém, deve ser exercitado até o final do curso e estendido à sua prática docente, de modo a superar a fragmentação da aprendizagem.

Esses componentes, em suma, são indispensáveis ao nosso Curso, haja vista as várias possibilidades de desenvolvermos projetos, articulando os conhecimentos diversos no contexto da formação da prática profissional do Licenciado em Letras.

Acreditamos que a proposta de Seminário Interdisciplinar pode relacionar as diferentes áreas do conhecimento, de modo a minimizar o saber fragmentado e a linearidade do currículo escolar. Assim, ao rompermos as fronteiras rígidas entre os componentes curriculares, é possível contextualizarmos os conteúdos estudados, promovendo a relação do estudante (alguns já professores) com o mundo.

Ademais, essa experiência vivenciada a partir do $2^{\circ}$ período favorece o desenvolvimento da pesquisa, tomando-a como princípio articulador da produção do 
conhecimento, conforme defende Freire (2013), ao afirmar que o ensinar exige pesquisa. Para ele, o educador não pode negar-se, no seu exercício docente, o seu compromisso de reforçar a capacidade crítica do educando.

Não há ensino sem pesquisa e pesquisa sem ensino. Esses quefazeres se encontram um no corpo do outro. Enquanto ensino contínuo buscando, reprocurando. Ensino porque busco, porque indaguei, porque indago e me indago. Pesquiso para constatar, constatando, intervenho, intervindo educo e me educo. Pesquiso para conhecer e o que ainda não conheço e comunicar ou anunciar a novidade" (FREIRE, 2013, p. 32).

As ações integradoras construídas a partir dos Seminários Interdisciplinares do curso de Letras do IFPB, associando ensino e pesquisa, promove, certamente, maior efetividade na formação integral do educando, posto que o uso de tais metodologias reflexivas podem provocar uma prática permanente de investigação nas ações regulares de sala de aula. Em outras palavras, o processo de construção e reconstrução do fazer pedagógico se realiza, e, como consequência, teremos cidadãos mais autônomos, capazes de construir e reconstruir seus saberes.

No que diz respeito à Literatura, levando-se em consideração que o seu lugar na escola ainda é incerto e muitos professores ainda encontram dificuldade na compreensão do seu objeto de estudo no ensino básico, os Seminários Interdisciplinares II e IV, cuja atenção especial se volta para essa área do conhecimento, apresentam-se como de extrema relevância para o docente em formação, uma vez que práticas metodológicas podem ser investigadas e experimentadas; e estudos pertinentes à leitura literária e ao papel da Literatura no ensino básico podem ser implementados no percurso desses componentes curriculares - vivências, infelizmente, ainda raras na formação docente inicial.

\section{REFERÊNCIAS}

BRASIL. Resolução MEC/CNE/CP no. 2, de $1^{\mathbf{0}}$ de julho de 2015. Define as Diretrizes Curriculares Nacionais para a formação inicial em nível superior (cursos de licenciatura, 
cursos de formação pedagógica para graduados e cursos de segunda licenciatura) e para a formação continuada. Disponível em: http://pronacampo.mec.gov.br/images/pdf/res_cne_cp_02_03072015.pdf>. Acesso em: 21 jan. 2017.

DEMO, P. Professor do futuro e reconstrução do conhecimento. Petrópolis: Rio de Janeiro: Vozes, 2004.

DOS SANTOS, A.F. de A.; WINKELERD, M.S.B. A crise da leitura na formação docente: uma análise das práticas leitoras dos futuros professores. In: IX AMPED SUL. Anais. Caxias do Sul-RS: Universidade de Caxias do Sul, 2012. Disponível em: <http://www.portalanpedsul.com.br/admin/uploads/2012/Alfabetizacao,_Leitura_e_Esc rita/Trabalho/05_07_24_2717-6604-1-PB.pdf>. Acesso em: 25 jun. 2016.

FONTANA, M. I. A pesquisa na história da formação do pedagogo no Brasil: desafios políticos e pedagógicos. HISTDEBR. Campinas: Unicamp, 2007. Disponível em: < http://www.histedbr.fe.unicamp.br/acer_histedbr/encontro/encontro1/trab_pdf/t_maria\% 20iolanda\%20fontana.pdf>. Acesso em: 07 fev. 2017.

FORMIGA, G.M.; DUARTE, C.R. O cenário da Educação a distância no Instituto Federal da Paraíba. In: XI CONNEPI. Anais. Maceió-AL. No prelo 2017.

FREIRE, P. Pedagogia da autonomia: saberes necessários à prática educativa. 44. ed. Rio de Janeiro: Paz e Terra, 2013.

INSTITUTO FEDERAL DE EDUCAÇÃO CIÊNCIA E TECNOLOGIA DA PARAÍBA. Projeto Pedagógico do Curso de Licenciatura em Letras na modalidade a distância. IFPB, 2012.

Ambiente Virtual de Aprendizagem. 2017. Disponível em: <www.ifpb.edu.br/ead. Acesso em: 11 fev. 2017.

MARTINS, I. Literatura em sala de aula: da teoria literária à prática escolar. Anais do Evento Pós-Graduação em Letras, v. 30, p. 514-552, 2005. Disponível em: $<$ http://s3.amazonaws.com/academia.edu.documents/31603280/5.2_Ivanda.pdf?AWSA ccessKeyId=AKIAIWOWYYGZ2Y53UL3A $\&$ Expires $=1485353829 \&$ Signature $=$ YlgF 
BwhfTc7KQXfMTRyBFV9Qg4Q\%3D\&response-contentdisposition=inline\%3B\%20filename\%3D5_2_Ivanda.pdf.>. Acesso em: 9 abr. 2015. SILVA, R.N. da; CHAVES P.M.; GHIGGI, G. In: IX AMPED SUL. Anais. Caxias do Sul-RS: Universidade de Caxias do Sul, 2012. Disponível em: <http://www.ucs.br/etc/conferencias/index.php/anpedsul/9anpedsul/paper/viewFile/267 6/578>. Acesso em: 06 fev. 2017.

THIESEN, J. da S. A interdisciplinaridade como um movimento articulador no processo ensino-aprendizagem. Revista brasileira de educação, v. 13, n. 39, p. 545, 2008. Disponível em: < http://www.famam.com.br/admin/anexos/24-022015_05_09_36_.pdf>. Acesso em: 19 out. 2014.

\section{Cristina Rothier Duarte}




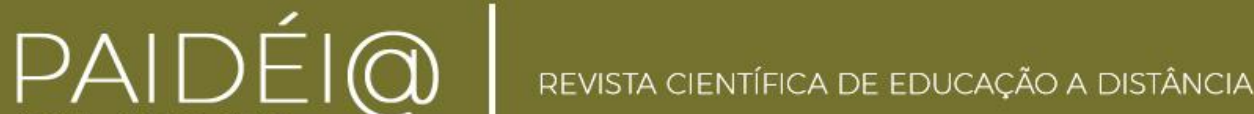

Especialista em Ciências da Linguagem com Ênfase no Ensino da Língua Portuguesa UFPB, Bacharel em Direito - UFMT, graduanda em Letras - língua portuguesa - IFPB, mestranda em Letras - PPGLE UFPB

\section{Girlene Marques Formiga}

Doutorado em Letras pela Universidade Federal da Paraíba, Brasil(2009) Classe D Padrão/nível 404 do Instituto Federal de Educação, Ciência e Tecnologia da Paraíba , Brasil

\section{Márcia de Oliveira Alves}

Doutoranda em Humanidades e Artes, graduação em Ciência da Computação pela Universidade de Marília (1992), especialista em Planejamento Educacional e em Educação a distância, professora do CEFET MT desde 1994, redistribuída para o IFPB em 2008.

\section{Artigo recebido em 07/07/2018 Aceito para publicação em 29/01/2019}

\section{Para citar este trabalho:}

DUARTE, Cristina Rothier; FORMIGA, Girlene Marques; ALVES, Marcia de Oliveira. PESQUISA EM LITERATURA E INTERDISCIPLINARIDADE: UM RELATO DE EXPERIÊNCIA NA FORMAÇÃO DOCENTE EAD. Revista Paidéi@. Unimes Virtual. Volume 11 - Número 19 - JANEIRO -2019 - Disponível em: 